\title{
Social inequalities in protective behaviour uptake at the start of the COVID-19 pandemic: results from a national survey
}

\author{
Alexandra Blair ${ }^{1}$ (D) $\cdot$ Abtin Parnia ${ }^{1} \cdot$ Faraz V. Shahidi $^{2} \cdot$ Arjumand Siddiqi $^{1,3}$
}

Received: 25 November 2020 / Accepted: 9 June 2021 / Published online: 19 August 2021

(C) The Canadian Public Health Association 2021

\begin{abstract}
Objectives We aimed to assess social patterns of handwashing, social distancing, and working from home at the start of the COVID-19 pandemic in Canada, and determine what proportions of the overall prevalence and social inequalities in handwashing and social distancing are related to inequalities in the opportunity to work from home, to guide pandemic preparedness and response.

Methods Using cross-sectional data from the Canadian Perspectives Survey Series, collected between March 29 and April 3, 2020, among Canadian adults $(N=4455)$, we assessed prevalence of not working from home, social distancing in public, or practicing frequent handwashing, according to age, sex, marital status, immigration, education, chronic disease presence, and source of COVID-19 information. Multivariate regression, population attributable fraction estimation, and generalized product mediation analysis were applied.

Results Absence of frequent handwashing and distancing was more common among those working outside than within the home (prevalence differences of 7\% (95\% CI: 4, 10) and 7\% (95\% CI: 3, 10), respectively). Inequalities in handwashing and distancing were observed across education and immigration status. Over $40 \%$ of the prevalence of non-uptake of handwashing and distancing was attributable to populations not being able to work from home. If all worked from home, over $40 \%$ (95\% CI: 8, 70) of education-based inequalities in handwashing and distancing could be eliminated, but differences by immigration status would likely remain.

Conclusion For pandemic response, both workplace safety initiatives and mechanisms to address the inequitable distribution of health risks across socio-economic groups are needed to reduce broader inequalities in transmission risk.
\end{abstract}

\section{Résumé}

Objectifs Nous avons cherché à évaluer les habitudes sociales en matière d'hygiène des mains, de distanciation physique et de travail à domicile au début de la pandémie de la COVID-19 au Canada, et à déterminer quelles proportions de la prévalence globale et des inégalités sociales en matière d'hygiène des mains et de distanciation physique sont liées aux inégalités dans la possibilité de travailler à domicile (le télétravail), afin de guider la préparation et la réponse à la pandémie.

Méthodes À l'aide des données transversales de la Série d'enquêtes sur les perspectives canadiennes 1, recueillies entre le 29 mars et le 3 avril 2020 auprès d'adultes canadiens ( $N=4455)$, nous avons évalué la prévalence du travail hors du domicile, de la non-distanciation physique en public et de l'absence de lavage fréquent des mains, en fonction de l'âge, du sexe, de l'état civil, de l'immigration, de l'éducation, de la présence de maladies chroniques et de la principale source déclarée d'information sur la COVID-19. Une régression multivariée, une estimation de la fraction attribuable dans la population et une analyse de médiation par produit généralisé ont été appliquées.

Alexandra Blair

alexandra.blair@utoronto.ca

1 Dalla Lana School of Public Health, University of Toronto, 155 College Street, Toronto, ON M5T 3M7, Canada

2 Institute for Work \& Health, Toronto, ON, Canada

3 Gillings School of Global Public Health, University of North Carolina-Chapel Hill, Chapel Hill, NC, USA 
Résultats L'absence de lavage fréquent des mains et de distanciation physique étaient déclarées plus fréquemment chez les personnes travaillant à l'extérieur qu'à l'intérieur du domicile (différences de prévalence de $7 \%$ (IC $95 \%: 4,10$ ) et $7 \%$ (IC $95 \%: 3,10$ ), respectivement). Des inégalités en matière de lavage fréquent des mains et de la pratique de distanciation physique ont été observées en fonction du niveau d'éducation et du statut d'immigration. Plus de $40 \%$ de la prévalence de la non-pratique du lavage fréquent des mains et de la distanciation physique était attribuable au fait que les populations ne pouvaient pas travailler à domicile. Si toutes les personnes travaillaient à domicile, plus de $40 \%$ (IC $95 \%: 8,70$ ) des inégalités liées au niveau d'éducation en matière de lavage des mains et distanciation physique pourraient être éliminées, mais les inégalités au niveau du statut d'immigration en matière de ces deux comportements subsisteraient probablement.

Conclusion Pour la répondre à la pandémie, il faut à la fois des initiatives de sécurité au travail, ainsi que des mécanismes visant à remédier à la répartition inéquitable des risques sanitaires entre les groupes socio-économiques pour réduire les inégalités plus larges en matière de risque de transmission.

Keywords COVID-19 $\cdot$ SARS-CoV-2 $\cdot$ Behaviour $\cdot$ Prevention $\cdot$ Health equity $\cdot$ Canada

Mots-clés COVID-19 · SRAS-CoV-2 · comportement · prévention · équité en matière de santé · Canada

\section{Introduction}

To prevent the transmission of the coronavirus disease (COVID-19)-causing severe acute respiratory syndrome coronavirus 2 (SARS-CoV-2), several behavioural changes have been encouraged, including practices of social distancing, increased handwashing, and when possible, working from home. Public health theory and research (Andersen 2008; Bandura and Walters 1977; Sen 1993; Solar and Irwin 2010) indicate that, above and beyond individual beliefs (Rosenstock 1974), the uptake of health-related behaviours is heavily determined by social determinants, such as gender, race, income, education, occupation, and housing, which facilitate or constrain opportunities to engage in these behaviours (Cohn 2014; Semenza 2010).

Evidence from past outbreaks of genetically similar coronaviruses to SARS-CoV-2 is limited, though available studies suggest that several of these determinants - namely gender, education, and occupation-were associated with the uptake of protective measures like frequent handwashing and social distancing following SARS-CoV-1 outbreaks in 2002 and MERS-CoV in 2012 (Lau et al. 2003; Quah and Hin-Peng 2004; Tan et al. 2004; Yang et al. 2019). In the COVID-19 era, a growing body of evidence corroborates these earlier findings. First, evidence from several countries of large racial and socio-economic inequalities in COVID-19 incidence (Chen et al. 2020; Chung et al. 2020) is highly suggestive of social inequalities in SARS-CoV-2 exposure. Second, some of the largest COVID-19 outbreaks have so far been observed in settings where social distancing is difficult to achieve, such as long-term care homes, prisons, and meatpacking facilities (Günther et al. 2020; Solis et al. 2020). Furthermore, certain occupations are associated with higher likelihood of mortality from COVID-19 (Chen et al. 2021). Third, studies that examined the uptake of health-related behaviours have also found that several social determinants of health are associated with the likelihood of handwashing (Alsan et al. 2020; Brown et al. 2020) and social distancing (Atchison et al. 2021; Brankston et al. 2021; Garnier et al. 2021; Jay et al. 2020; Weill et al. 2020). Specifically, employment status has been identified as one of the important indicators of ability to take up protective behaviours (Brankston et al. 2021). Despite this early evidence, equity-related COVID-19 data are still relatively limited (Blair et al. 2021; Upshaw et al. 2021). The studies so far have been mostly descriptive and have not tested the mechanisms underlying the relationship between social determinants of health and the uptake of these behaviours.

In this study, we address these gaps in the literature by drawing on a nationally representative sample of Canadians aged 15 years and older who participated in the Canadian Perspectives Survey Series (CPSS) between March 29 and April 3, 2020 (Statistics Canada 2020d), to assess how the uptake of protective behaviours was socially patterned across Canadian society at the start of the pandemic. At the time of data collection, COVID-19 had just been declared a global pandemic (March 11). Cumulative COVID-19 case counts were still relatively limited across provinces and territories $(N=6255$ in Canada overall; $n=2840$ in Quebec, $n=1355$ in Ontario, $n=884$ in British Columbia, $n=621$ in Alberta, and less than $n=200$ in the other jurisdictions on March 29, 2020) (Public Health Agency of Canada 2021). Travel and border restrictions had recently been introduced in Canada (March 16), and many jurisdictions had started to close non-essential workplaces. However, it was before the scientific community understood the details of the modes of SARS-CoV-2 transmission (e.g., droplet or aerosol transmission versus fomite transmission), before jurisdictions (including the Chief Public Health Officer of Canada) urged or mandated the wearing of non-medical masks when in public, and before subsequent waves of the pandemic, between and across which jurisdictions eased "shutdown" restrictions (Vogel 2020). Using the very first wave of 
the CPSS, this study provides a baseline assessment of social inequalities in behaviour uptake, and of the potential mechanisms explaining observed social inequalities, at the start of the pandemic, using the best possible source of Canadian data. Having this baseline is essential to assess how behaviours and critical social determinant pathways may have changed throughout the pandemic in Canada.

Our primary objective was to assess the associations between individual-level social characteristics and the uptake of three behavioural outcomes: increased handwashing, social distancing, and working from home. As behaviour uptake may be influenced by individuals' ability to work from home, our second objective was to assess what proportion of the population prevalence of the absence of handwashing and social distancing behaviours was attributable to those employed not being able to work from home. Our third objective was to estimate the proportion of social inequalities in behaviour prevalence that could be eliminated if all who were employed could work from home.

\section{Methods}

\section{Data and sample}

We conducted a cross-sectional study using data from the first wave of Statistics Canada's CPSS. The CPSS is a voluntary online survey sent to a subsample of respondents to Statistics Canada's Labour Force Survey (LFS). The CPSS captures a nationally representative sample of residents aged 15 years and older of all ten of the country's provinces. The sampling frame includes fulltime members of the Canadian Armed Forces, and excludes residents in the territories, and institutions and populations living in remote areas or areas with low population density, or on First Nation reserves and other settlements (Statistics Canada 2020d). CPSS data collection occurred between March 29 and April 3, 2020 (capturing the labour market reference period from March 22 to March 28, 2020, behaviours and policy impacts occurring between March 29 and April 3, 2020) (Statistics Canada 2020a). A sign-up survey was performed between January 15 and March 15, 2020; $n=7242$ (23\%) agreed to participate and were sent the survey link, and $n=4627$ (64\%) participated in the survey (cumulative response rate of 15\%) (Statistics Canada 2020d).

\section{Measures}

Several conceptual frameworks have been proposed to explain the determinants of health-related behaviours, and their relationships. In this study, we utilize Andersen's Health Behaviour Model (Andersen 2008), which is useful for its easy adaptation to a wide range of health behaviours (after its original design of measuring behavioural uptake of healthcare services), and for the structure it provides to help outline the assumed relationships between "predisposing", "enabling", and "need-related" determinants, which facilitate or constrain opportunities to engage in these behaviours and shape unfair and avoidable health inequalities (i.e., health inequities) (Arcaya et al. 2015; von Lengerke et al. 2014). Figure 1 summarizes the assumed associations between study measures, including individual-level social characteristics and behavioural outcomes, structured using an adaptation of Andersen's Health Behaviour Model (Andersen 2008). A list of survey questions used to derive our study measures is provided in Supplementary File 1.

\section{Predisposing, enabling social characteristics, and need-related factors}

Individual-level social characteristics measured were age (15-24, 25-44, 45-64, 65 years and older), sex (male, female), marital status ("partnered", i.e., married or living with a common-law partner, or "not partnered", i.e., single, widowed, or separated), immigrant status (immigrant, born in Canada) and educational attainment (less than high school, high school diploma to collegiate, bachelor's degree and above) (Fig. 1). The CPSS did not collect information on respondents' race or ethnicity, gender identity, income level, household size, caregiving status, nor sector or type of employment.

Insofar as behavioural changes can also be determined by one's personal risk assessment and perceived "need" or by perceived experts' recommendations (Fig. 1) (Andersen 2008), we also measured respondents' self-report of chronic conditions (i.e., "compromised immune system", "diabetes", or "a chronic condition affecting your lungs, heart, or kidneys"), which are known to be associated with a higher risk of COVID-19 complication (Chow et al. 2020), and their primary source of COVID-19-related information. Three groups of sources were used: news media; social contacts (friends, family) or social media; and official health or public health sources (municipal, provincial, or federal health sources, health professionals, workplace, or schools).

\section{Health-impacting behaviours: handwashing, social distancing in public, working from home}

Respondents were asked to indicate which of a list of precautions they took to reduce their risk of exposure to SARS-CoV-2. In this study, we assessed whether respondents indicated that they had adopted (yes/no) any of the following behaviours: "washed your hands more regularly"; "used social distancing when out in public (i.e., made changes in your everyday routine to minimize close contact with others)"; and "worked from home". Social distancing or "physical distancing" refers to the recommended act of keeping 
Fig. 1 A summary of potential individual-level social determinants of personal health practices to prevent COVID-19 infection presented using an adaptation of Andersen's Health Behavioural Model (2008)

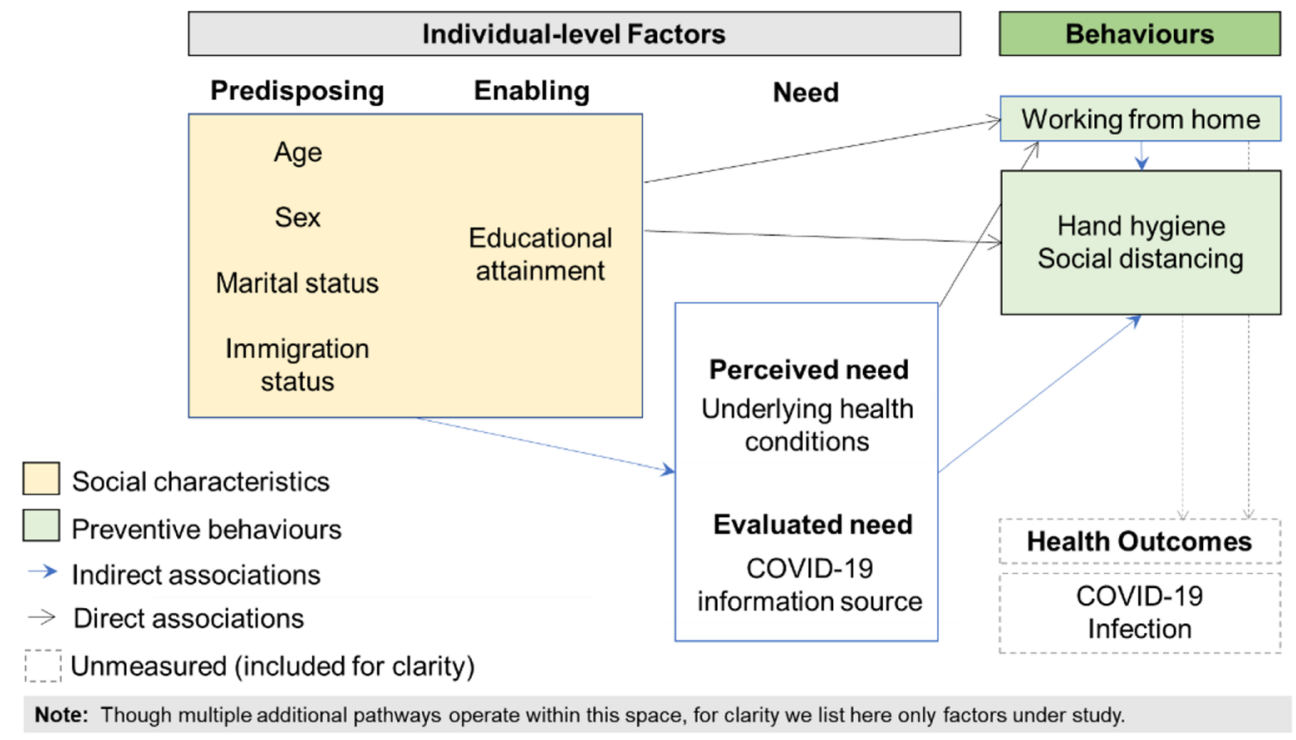

For the second objective of assessing what proportion of

a space of $2 \mathrm{~m}$ or 6 feet from those who are not part of one's household, to limit face-to-face contact and potential spread of SARS-CoV-2 (Public Health Agency of Canada 2020). The measure indicating whether respondents "worked from home" was used in combination with a question asking whether respondents were currently employed, allowing for a comparison of the following three groups: those who reported being employed and working from home; those who reported being employed and not working from home; and those who reported not being employed. This measure was also assessed as a potential mediating factor in the relationship between social characteristics and behaviours of handwashing and social distancing. The CPSS 1 questionnaire did not include items on other protective behaviours, such as the use of non-medical masks or face coverings. The use of non-medical masks was only recommended by Canadian federal public health officials as of April 6, 2020, after the CPSS 1 data collection period had been completed.

\section{Analysis}

For the primary objective of assessing associations between individual-level social characteristics and the uptake of handwashing, social distancing, and working from home, first, descriptive analyses were used to assess the distribution of behaviours across social characteristics. Then, multivariate logistic regression models were used to assess the covariateadjusted associations (expressed as odds ratios) between each social characteristic and behaviour. As measures of COVID19 information source and chronic disease presence may contribute to the confounding of the associations between workplace status and behaviours (Supplementary File 2, Figure S1), models were also adjusted for these factors. Using predicted probabilities from the latter models, covariate-adjusted behaviour prevalence differences (PD) were computed (Williams 2012). the population prevalence of the absence of handwashing and social distancing behaviours was attributable to those employed not being able to work from home, predicted probabilities obtained from the modeling output for the first objective were used to contrast potential covariate-adjusted behaviour prevalence estimates across two possible scenarios: one where all measure values remained the same, the other where all those employed were working from home (Newson 2013). This yielded the proportion of the population prevalence (population attributable fractions or "PAF") of the absence of handwashing and social distancing that was attributable to those employed and not able to work from home (Newson 2013).

Assuming that place of work may represent a mediating factor ("mediator") between social characteristics and behaviours such as handwashing and social distancing, the third objective was to estimate the proportion of social inequalities in handwashing and distancing behaviour that could be eliminated if all who were employed could work from home. For this objective, we applied the generalized product mediation analysis method, which requires three steps (Naimi et al. 2016). First, a covariate-adjusted generalized linear logbinominal link model was used to estimate the total adjusted association (referred to as the total effect or "TE") between social characteristics and each behaviour, respectively, without adjustment for the mediator variable of workplace status. As a second step, these models were adjusted for workplace status (i.e., setting the hypothetical mediator value such that all worked from home). As recommended for this method (VanderWeele 2015), at this modeling step, product terms between the social characteristics and workplace status were tested to account for potential heterogeneity of the effect of workplace status on behaviours across social groups (no effect modification was observed). The coefficient values in these 
mediator-adjusted models are assumed to yield the direct associations between the social characteristics and the behaviours (referred to as the controlled direct effect or "CDE"). In a counterfactual framework (Naimi et al. 2016), if we assume having measured all mediator-outcome confounders, the $\mathrm{CDE}$ can be defined as the remaining covariate-adjusted social inequality in behaviour prevalence had all individuals been assigned (possibly counterfactually) the protective mediator values (i.e., working from home) (Naimi et al. 2016). If the social inequalities in work location explain, at least in part, broader social inequalities in protective behaviour uptake, we would expect to see a proportion of the inequality eliminated. The proportion eliminated was estimated on an excess relative risk scale (using relative risk [RR] estimates from TE and CDE models (Naimi et al. 2016)) as follows: (RR ${ }^{\mathrm{TE}}$ $\mathrm{RR}^{\mathrm{CDE}}$ / $\left(\mathrm{RR}^{\mathrm{TE}}\right.$-1) (VanderWeele 2015). Confidence intervals were estimated using the bootstrap method (1000 replications) (VanderWeele 2015). Since the estimation of the PE relies on the assumption of no unmeasured confounding of the mediator-outcome relationship (VanderWeele 2015), we assessed how large associations would have to be between an unmeasured factor and both the mediator and outcome for the true PE estimates to be null (0\%) applying bounding formulas (VanderWeele 2016).

All analyses were conducted using Stata 16 (StataCorp, L.L.C. Stata statistical software: release 16. College Station, TX, 2019). This project was approved by the Canadian Research Data Centre at the University of Toronto, and was exempt from ethics review due to secondary use of anonymized survey data.

\section{Results}

Of the CPSS sample ( $N=4455), 52 \%$ were female, $47 \%$ were younger than 45 years of age, $22 \%$ were immigrants, $63 \%$ were partnered, $28 \%$ had a bachelor's degree, $14 \%$ had less than a high school diploma, and $51 \%$ were employed (Table 1) - slightly less than what was observed (62\% employed) in the general population in January 2020 (and March 2019) (Statistics Canada 2020b, 2020c). Approximately $18 \%$ of the sample reported having at least one chronic condition (Table 1). Regarding COVID-19 information source, $35 \%$ reported utilization of official public health publications, their school or work, $52 \%$ turned to news media, and $13 \%$ accessed information through friends, family, or social media (see Supplementary File 2, Table S1 for detailed use by social characteristics).

\section{Social patterning of workplace status, handwashing, and social distancing behaviours}

Overall, $23 \%$ of respondents worked from home, $28 \%$ worked outside the home, and $49 \%$ were not employed (Table 1).
Compared with females, males were more likely to be employed and working outside of the home and less likely to be unemployed (Fig. 2). Unsurprisingly, unemployment was most common among those above 65 years ( $85 \%$ prevalence), due to retirement (Table 1). Working from home was most common among those with a bachelor's degree (45\% prevalence) compared with those who had less than a high school diploma (5\% prevalence) or up to collegiate education (17\% prevalence) (Table 1) - and these differences persisted after covariate adjustment (Fig. 2; odds ratio values are presented in Supplementary File 2, Table S2).

The majority ( $>85 \%)$ of respondents reported an uptake in handwashing and social distancing behaviours (Table 1). Overall, $8 \%$ of respondents reported not increasing their handwashing frequency and $13 \%$ reported not social distancing while in public. Absence of increased handwashing was more prevalent among those without a high school diploma (14\% prevalence) than among those with a bachelor's degree (5\% prevalence); and among those working outside the home (9\% prevalence) and those unemployed (10\% prevalence), compared with those working from home (3\% prevalence) (Table 1). These inequalities persisted after covariate adjustment (Fig. 3, Table S2). No statistically significant differences in the crude or covariate-adjusted prevalence of handwashing behaviours were observed according to chronic disease presence (Table 1, Fig. 3) or source of COVID-19 information (Table 1, Fig. 3).

Absence of social distancing was also more common among those without a high school diploma (19\% prevalence) and those with up to collegiate education (14\% prevalence) than those with a bachelor's degree ( $7 \%$ prevalence) (Table 1) - and this inequality persisted after covariate adjustment (Fig. 3, Table S2). The absence of social distancing was also more common among immigrant respondents and those who were not working from home (Fig. 3). In this early stage of the pandemic, younger adults were more likely to practice distancing than those aged over 65 years (Fig. 3, Table S2). No statistically significant differences in the crude or covariate-adjusted prevalence of social distancing behaviours were observed according to chronic disease presence (Table 1, Fig. 3) or source of COVID-19 information (Table 1, Fig. 3).

\section{The contribution of workplace status to the social patterning of handwashing and social distancing}

Adjusting for all covariates, up to $54 \%(95 \%$ CI 33,75$)$ of the population prevalence of no change in handwashing $(8 \%$ overall prevalence) and $40 \%(95 \%$ CI 17, 62) of the population prevalence of not practicing social distancing (overall $13 \%$ prevalence) may be attributable to individuals who were employed but not able to work from home (Supplementary File 2, Figure S3). 


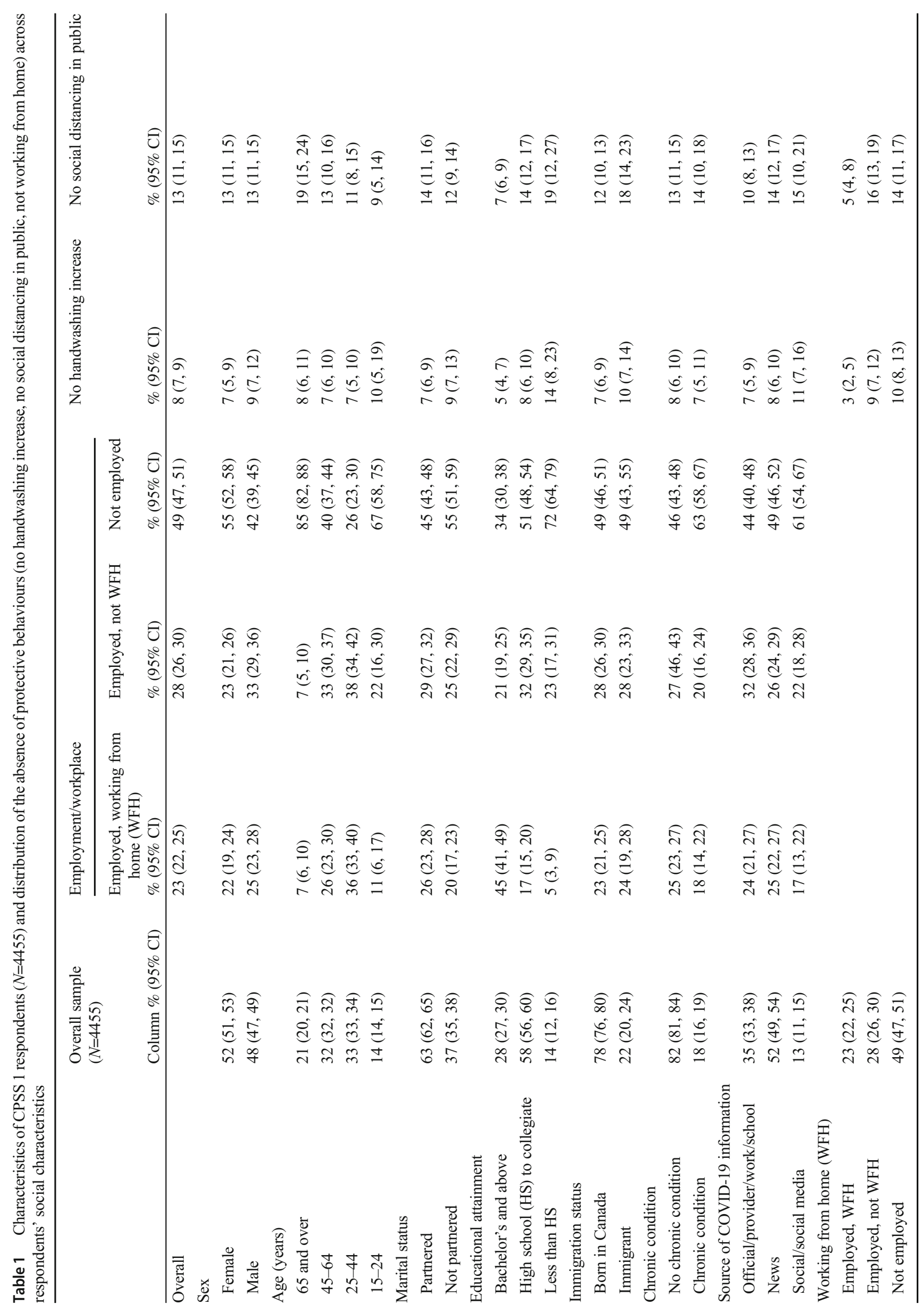



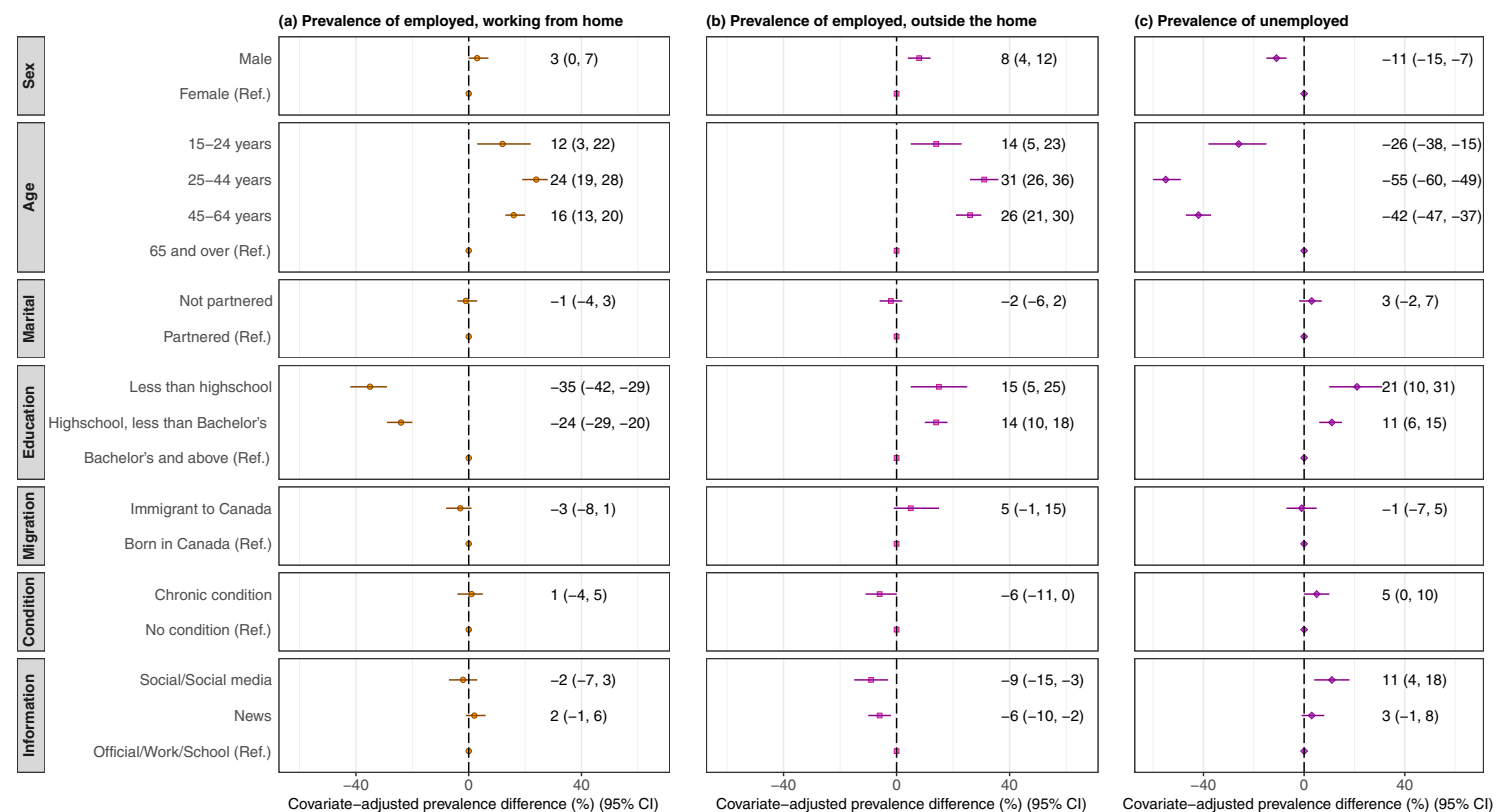

Fig. 2 Covariate-adjusted prevalence differences in a being employed and working from home, $\mathbf{b}$ being employed and not working from home, and c being unemployed across social characteristics of Canadian Perspectives Survey Series respondents $(N=4455)$
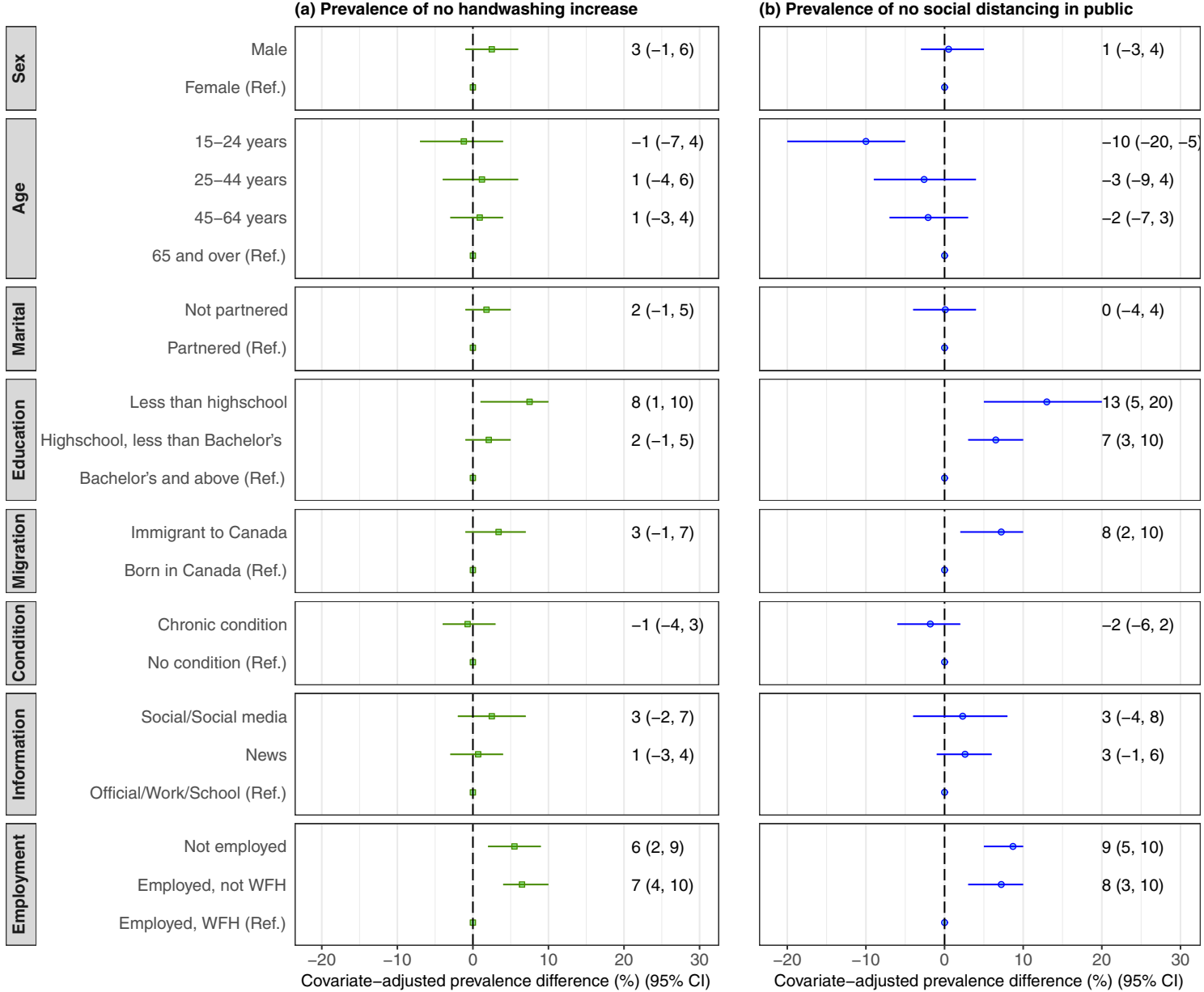

Fig. 3 Covariate-adjusted prevalence differences in a not increasing handwashing and $\mathbf{b}$ not social distancing in public across social characteristics of Canadian Perspectives Survey Series respondents $(N=4455)$ 
Among those employed, working from home was not estimated to be able to reduce the observed covariate-adjusted immigration-based inequalities in handwashing $\left(\mathrm{RR}^{\mathrm{TE}}=2.05\right.$ $(95 \%$ CI $1.20,3.60))$ or social distancing $\left(\mathrm{RR}^{\mathrm{TE}}=1.77(95 \%\right.$ CI 1.11, 2.82)); all proportion eliminated estimates crossed the null (Fig. 4).

However, it was estimated that large proportions ( $>40 \%)$ of the observed covariate-adjusted education-based inequalities in handwashing (up to collegiate versus bachelor's degree $\mathrm{RR}^{\mathrm{TE}}=1.99(95 \%$ CI $\left.1.20,3.30)\right)$ and social distancing $(<$ high school versus bachelor's degree $\mathrm{RR}^{\mathrm{TE}}=2.56$, (95\% CI 1.27 ,
5.15); up to collegiate versus bachelor's degree $\mathrm{RR}^{\mathrm{TE}}=1.94$ (95\% CI 1.24, 3.04)) could be eliminated if all worked from home (Fig. 4) (full model output in Supplementary File 2, Table S3).

Though observed covariate-adjusted inequalities in behaviours are likely robust to potential unmeasured confoundingwith an unmeasured factor having to have as large an association with the behavioural outcomes than any of the observed measures in the study (i.e., RR $>3$ to 5, Tables S3-S5) proportion-eliminated estimates should be interpreted with caution, given that they may be explained away if an

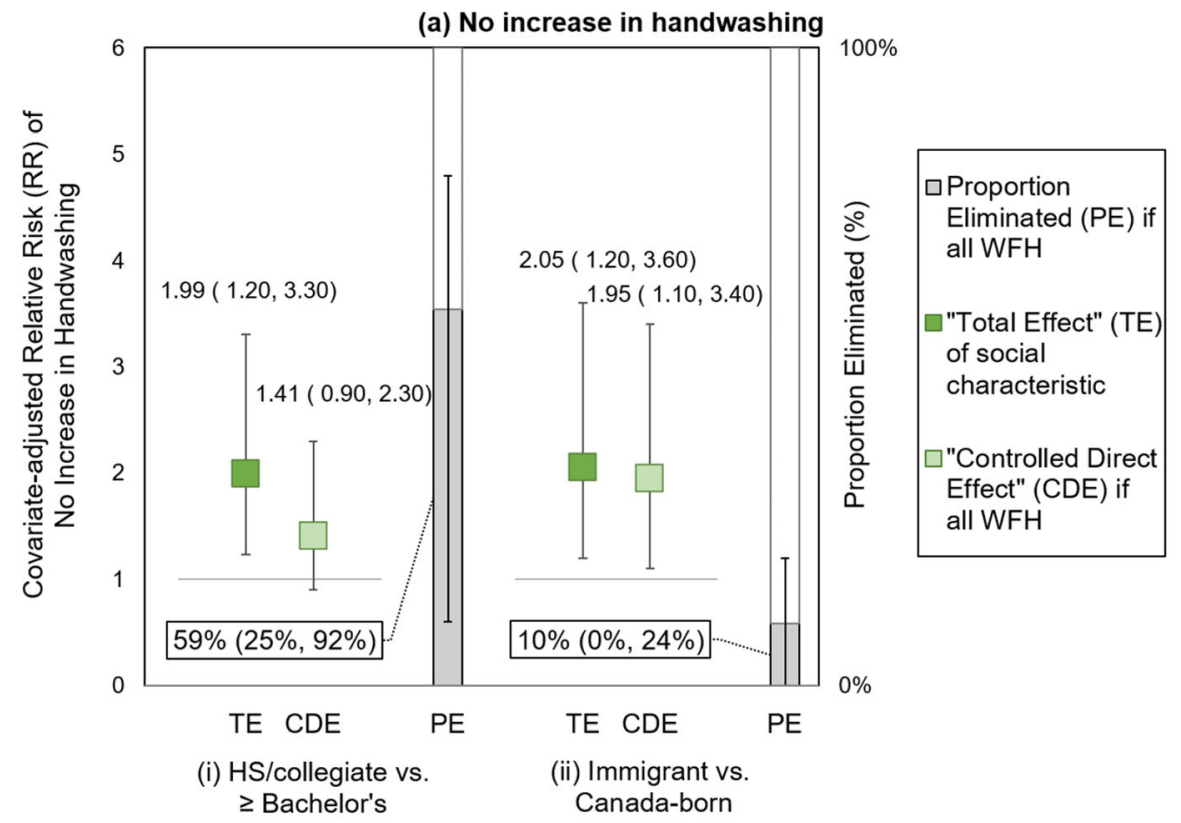

(b) No social distancing in public

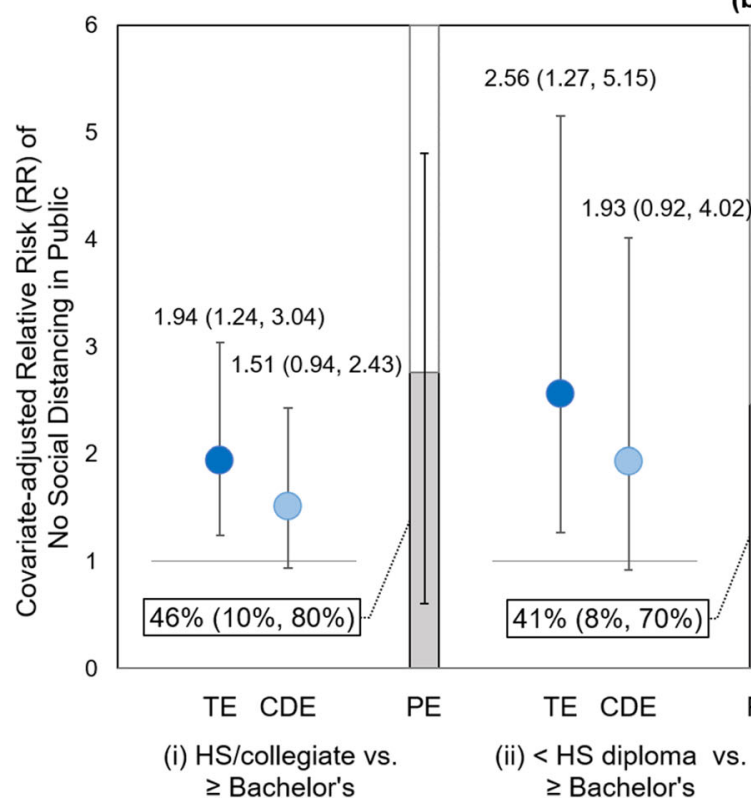

Fig. 4 Among employed Canadian Perspectives Survey Series respondents $(N=2407)$, covariate-adjusted "total effect" (TE) and "controlled direct effect" (CDE) (if all worked from home [WFH]) of lower
$100 \%$

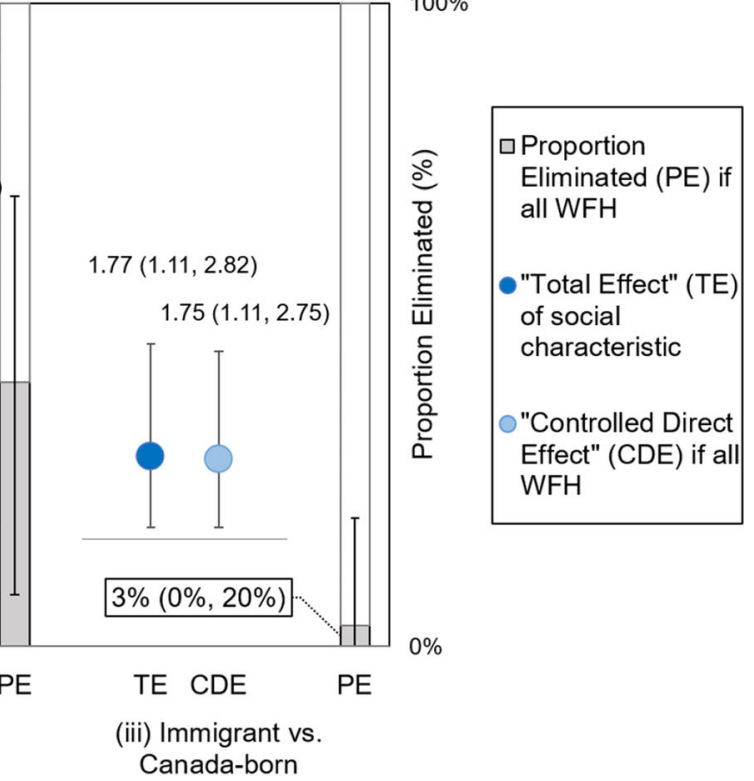

education and immigration status on a no increase in handwashing and b no social distancing in public - and the proportion of the inequalities that could be eliminated (PE) if all worked from home 
unmeasured confounder has an association of $R R=2$ to 2.5 with the mediator and outcome (i.e., as large as the association for education and immigration status and these behaviours) (Table S5). Measures such as race/ethnicity and income were not included in the CPSS 1 questionnaire and would be important to consider as potential confounders in future studies.

\section{Discussion}

In a nationally representative sample of Canadian adults, three behaviours that are known to be protective of SARS-CoV-2 transmission-working from home, increased handwashing, and social distancing - tended to be socially patterned, with the most prominent inequalities observed across groups by age, educational attainment, and immigration status. Behaviours such as increased handwashing and social distancing were strongly associated with respondents' employment and workplace status. Overall, over $50 \%$ of the population prevalence of not increasing handwashing, and $40 \%$ of the population prevalence of not social distancing in public were attributable to those employed not being able to work from home. Mediation analyses suggest that between $40 \%$ and $60 \%$ of the observed education-based inequalities in both behaviours could be eliminated if everyone, regardless of education status, could work from home. However, workplace status did not appear to mediate the association between immigration status and behaviour uptake - indicating that other determinants are likely driving this inequality.

Findings of educational attainment and occupation-related social inequalities in individual-level uptake of protective behaviours such as handwashing are consistent with those observed in other jurisdictions (Atchison et al. 2021) as well as during previous outbreaks of respiratory diseases, such as MERS-CoV and SARS-CoV (Quah and Hin-Peng 2004; Yang et al. 2019). Aligned with our adaptation of Andersen's Health Behaviour Model (Andersen 2008), educational attainment appears to represent an "enabling" determinant of health behaviour, namely by shaping individuals' opportunity to work from home. The finding that education-based inequalities in behavioural changes are likely attributable to not being able to work from home is aligned with previous suggestions that lower socio-economic status (SES) workers may be less likely to socially distance because of their work in dense social spaces (Barbieri et al. 2020; European Centre for Disease Prevention and Control 2020). These findings are aligned with public health findings that health risks tend to be distributed unevenly across society according to individuals' social and economic position (Link and Phelan 1995).

The results of this study suggest that, during the early lockdown, an important barrier to protective behaviour uptake was workplace status. Some jobs were "riskier" because they could not be done from home, and these tended to be held by those with less education. These findings have several implications for pandemic preparedness and response planning (Haworth-Brockman and Betker 2020). Firstconsistent with the "hierarchy of controls" concept in hazard prevention (Centers for Disease Control and Prevention 2015; Dehghani et al. 2020) - our results highlight the need to mitigate risk in employment spaces. This can include the implementation of evidence-based guidelines, regulations, and enforcement strategies so that employees can easily take up protective behaviours across workplace environmentsincluding break and changing rooms, dormitories, and transport services (European Centre for Disease Prevention and Control 2020). These interventions would complement recommended structural changes, such as well-maintained ventilation systems, regular testing protocols, provision of and sufficient training regarding personal protective equipment, and ensuring the health, employment, and income protection for those diagnosed with COVID-19 (European Centre for Disease Prevention and Control 2020). Second, broader policy measures may be warranted to protect the health of vulnerable workers who are disproportionately exposed to "risky" workplaces - many of which are also "risky" in the sense that they are low paying and precarious (Benach et al. 2014; McClure et al. 2020). Workplace rights protections (De Maio and Kemp 2010) and compensatory measures to offset these co-occurring socio-economic risks could include higher wages, greater job security, and improved social protections such as access to hazard pay and paid sick days during public health emergencies (Hecker 2020; Yearby and Mohapatra 2020). These measures may be needed to ensure that workplace conditions do not reinforce and perpetuate the socioeconomic marginalization of vulnerable groups such as immigrants and those with lower educational attainment.

Third, outside of the workplace, interventions that reduce the overall distribution of health risks across vulnerable groups may also contribute to reducing inequalities in the uptake of protective behaviours, and COVID-19 incidence. For instance, since household contacts are at high risk of infection (Bi et al. 2020), and since crowded and multigenerational households are more common among immigrant populations (Haan 2011) and low-income earners (Tam 2021), interventions to ensure sufficient space for households to practice self-isolation are needed (Tam 2021). Strategies that have been recommended to improve overall access to quality housing include interventions to increase access to affordable housing (e.g., investment in social housing (Novac et al. 2002)) and income support (e.g., increased governmental transfers to families, and the proposed development of provincial and national poverty eradication strategies (Frank et al. 2020)). By addressing underlying inequalities in exposure risk, these primary prevention strategies may help reduce the overall disparities in SARS-CoV-2 transmission and health overall (Badets et al. 2020). Inequalities in other environmental exposures, such as immigration-based disparities in reliance on public transit (Heisz and Schellenberg 2004; Lachapelle and Pinto 2016) where social 
distancing may be less feasible (Sy et al. 2020), also warrant consideration. According to the 2001 census, $21 \%, 36 \%$, and $49 \%$ of individuals who had immigrated to Canada in the previous 10 years reported use of public transportation in Vancouver, Toronto, and Montreal, respectively, compared with $11 \%, 21 \%$, and $22 \%$ of Canadian-born residents in those cities, respectively (Heisz and Schellenberg 2004). Be it with regard to transit, housing, or income, scholars have emphasized that reductions in inequalities in access to health-promoting resources represent a mechanism to improve communities' resilience to public health crises (Haworth-Brockman and Betker 2020).

This study has several limitations to consider. First, the CPSS recorded a very low response rate, which threatens the generalizability of the study findings. Indeed, the unweighted CPSS sample over-represented those with higher education and under-represented those under 25 years of age as well as older Canadians (Statistics Canada 2020a, 2020d). All analyses presented herein were weighted, ensuring higher confidence in the generalizability of the results. Second, data collection for the CPSS took place over a relatively short time frame (i.e., 6 days). On the one hand, a longer time frame would likely have resulted in a higher response rate. On the other hand, given that respondents were asked questions about a specific labour market reference period (i.e., March 22 to March 28), a shorter time frame was likely optimal for minimizing the risk of recall bias. Third, this study explored a restricted number of individual-level social markers. Information was not available on respondents' race or ethnicity, Indigenous identity, gender, income level, household size, caregiving status, or local area-level social characteristics. Information describing the precise nature and characteristics of respondents' employment (e.g., sector, industry, income, occupation, and type of contract) was also lacking, prohibiting a detailed view of the relationship between work environment factors and behaviour change during the pandemic. Though it was estimated that the associations between social characteristics and behaviours are likely robust to potential unmeasured confounding, residual confounding is likely, and could potentially explain away observed mediation estimates. Studies that capture a broader range of social and economic measures are needed to better understand the pathways linking SES to protective behaviour uptake. Such studies will also be vital for generating more detailed and nuanced recommendations to inform pandemic response and preparedness. Fourth, measurement of self-reported behaviours is vulnerable to social desirability bias and differential reporting according to SES, which may lead to an over-estimation of behaviour uptake overall (Krumpal 2013), and a potential under-reporting of inequalities (Choi and Cawley 2018). Furthermore, the available questionnaire-based data did not allow a differentiation between handwashing behaviours across specific settings (home, at stores, while at work, etc.). This additional information would be useful to explore in future studies, allowing for more precise inequality and mediation measurement. Last, this study captures a snapshot of social inequalities in protective behaviours in the early phases of the COVID-19 pandemic in Canada. Studies of behaviour uptake at future time points are needed, to assess how potential public health restrictions and interventions throughout the pandemic may have influenced social inequalities across groups and jurisdictions.

\section{Conclusion}

Individual-level uptake of social distancing and hand-hygiene behaviours are essential to preventing the spread of COVID-19. However, uptake of these behaviours across society has not been equal, and this study suggests that the workplace was a key factor contributing to lower overall uptake as well as socio-economic inequalities in uptake in Canada. Workplace infection prevention and control protocols to enable behaviour uptake are needed, as are considerations of how social vulnerabilities across socioeconomic groups can be eliminated to prevent social inequalities during the COVID-19 and future pandemics.

\section{Contributions to knowledge}

What does this study add to existing knowledge?

- Using individual-level data, and both mediation analysis and population attributable fraction estimation, this study unpacks the mechanisms linking social characteristics, such as immigration status or education, to protective behaviour uptake.

- The study quantifies how much of the burden of the absence of handwashing and social distancing in the population overall, and the social inequalities in behaviour uptake, could potentially be eliminated if we could intervene on the risk pathway associated with working outside the home.

- Education-based inequalities in opportunities to work from home were found to partially mediate observed inequalities in handwashing and social distancing.

What are the key implications for public health interventions, practice, or policy?

- Aligned with previous findings, these results suggest that social and economic factors are likely root causes of protective behaviour uptake.

- These results highlight the need to mitigate risk in the workplace, through structural prevention strategies and social protections.

- Beyond the workplace, policy interventions that improve social and economic conditions may also contribute to reducing inequalities in the uptake of protective behaviours. 
Supplementary Information The online version contains supplementary material available at https://doi.org/10.17269/s41997-021-00553-0.

Acknowledgements We would like to thank Z. Zhao, A. Prencipe, and J. Jacob for their logistical support for this project. Although the research and analysis are based on data from Statistics Canada, the opinions expressed do not represent the views of Statistics Canada.

Funding This work was supported by the Fonds de Recherche du Québec-Santé (Postdoctoral Award); the Canadian Institutes of Health Research (Postdoctoral Award, Canada Research Chair in Population Health Equity) and the Institute for Work \& Health (Postdoctoral Award).

Data availability The data belong to Statistics Canada and are not publicly available.

Code availability The analysis code is not available for this project.

\section{Declarations}

Ethics approval This project was approved by the Canadian Research Data Centre at the University of Toronto. It was exempt from ethics review due to secondary use of anonymized, survey data.

Consent to participate Not applicable

Consent for publication Not applicable

Conflict of interest The authors declare no competing interests.

\section{References}

Alsan, M., Stantcheva, S., Yang, D., \& Cutler, D. (2020). Disparities in coronavirus 2019 reported incidence, knowledge, and behavior among US adults. JAMA Network Open, 3(6), e2012403. https:// doi.org/10.1001/jamanetworkopen.2020.12403.

Andersen, R. M. (2008). National health surveys and the behavioral model of health services use. Medical Care, 46(7), 647-653. https://doi.org/10.1097/MLR.0b013e31817a835d.

Arcaya, M. C., Arcaya, A. L., \& Subramanian, S. V. (2015). Inequalities in health: Definitions, concepts, and theories. Global Health Action, 8, 27106. https://doi.org/10.3402/gha.v8.27106.

Atchison, C. J., Bowman, L., Vrinten, C., Redd, R., Pristera, P., Eaton, J. W., \& Ward, H. (2021). Early perceptions and behavioural responses during the COVID-19 pandemic: A cross-sectional survey of UK adults. BMJ Open, 11(1). https://doi.org/10.1136/bmjopen2020-043577.

Badets, N., Novoa, G., \& Battams, N. (2020). COVID-19 impacts: Families and housing in Canada. Ottawa: The Vanier Institute of the Family. Available at: https://vanierinstitute.ca/download/27946/.

Bandura, A., \& Walters, R. H. (1977). Social Learning Theory (Vol. 1). Prentice-Hall.

Barbieri, T., Basso, G., \& Scicchitano, S. (2020). Italian workers at risk during the COVID-19 epidemic. Questioni di Economia e Finanza (Occasional Papers), 569. Bank of Italy, Economic Research and International Relations Area. Available at: https://ideas.repec.org/ p/bdi/opques/qef 569 20.html.

Benach, J., Vives, A., Amable, M., Vanroelen, C., Tarafa, G., \& Muntaner, C. (2014). Precarious employment: Understanding an emerging social determinant of health. Annual Review of Public Health, 35, 229-253.
Bi, Q., Wu, Y., Mei, S., Ye, C., Zou, X., Zhang, Z., . . Feng, T. (2020). Epidemiology and transmission of COVID-19 in 391 cases and 1286 of their close contacts in Shenzhen, China: A retrospective cohort study. The Lancet Infectious Diseases, 20(8), 911-919. https://doi.org/10.1016/S1473-3099(20)30287-5.

Blair, A., Warsame, K., Naik, H., Byrne, W., Parnia, A., \& Siddiqi, A. (2021) Identifying gaps in COVID-19 health equity data reporting in Canada using a scorecard approach. Canadian Journal of Public Health, 112(3), 352-362. https://doi.org/10.17269/s41997-021-00496-6.

Brankston, G., Merkley, E., Fisman, D. N., Tuite, A. R., Poljak, Z., Loewen, P. J., \& Greer, A. L. (2021). Socio-demographic disparities in knowledge, practices, and ability to comply with COVID-19 public health measures in Canada. Canadian Journal of Public Health, 112(3), 363-375. https:// doi.org/10.17269/s41997-021-00501-y.

Brown, L. G., Hoover, E. R., Barrett, C. E., Vanden Esschert, K. L., Collier, S. A., \& Garcia-Williams, A. G. (2020). Handwashing and disinfection precautions taken by U.S. adults to prevent coronavirus disease 2019, Spring 2020. BMC Research Notes, 13(1), 550. https://doi.org/10.1186/s13104-020-05398-3.

Centers for Disease Control and Prevention. (2015). The National Institute for Occupational Safety and Health (NIOSH): Hierarchy of controls. Retrieved from https://www.cdc.gov/niosh/topics/ hierarchy/default.html.

Chen, J. T., Waterman, P. D., \& Krieger, N. (2020). COVID-19 and the unequal surge in mortality rates in Massachusetts, by city/town and ZIP code measures of poverty, household crowding, race/ethnicity,and racialized economic segregation. Harvard Center for Population and Development Studies Working Paper Series, 25014(B25014 013E), B25014-25001E

Chen, Y.-H., Glymour, M., Riley, A., Balmes, J., Duchowny, K., Harrison, R., Bibbins-Domingo, K. (2021). Excess mortality associated with the COVID-19 pandemic among Californians 18-65 years of age, by occupational sector and occupation: March through October 2020. medRxiv, 2021.2001.2021.21250266. https://doi.org/10.1101/2021.01.21. 21250266.

Choi, A., \& Cawley, J. (2018). Health disparities across education: The role of differential reporting error. Health Economics, 27(3), e1e29. https://doi.org/10.1002/hec.3609.

Chow, N., Fleming-Dutra, K., Gierke, R., Hall, A., Hughes, M., Pilishvili, T., \& Ritchey, M. (2020). Preliminary estimates of the prevalence of selected underlying health conditions among patients with coronavirus disease 2019-United States, February 12-March 28, 2020. Morbidity and Mortality Weekly Report, 69(13), 382.

Chung, H., Fung, K., Ferreira-Legere, L. E., Chen, B., Ishiguro, L., Kalappa, G., et al. (2020). COVID-19 laboratory testing in Ontario: Patterns of testing and characteristics of individuals tested, as of April 30, 2020. Toronto: ICES. https://www.ices.on.ca/ Publications/Atlases-and-Reports/2020/COVID-19-LaboratoryTesting-in-Ontario.

Cohn, S. (2014). From health behaviours to health practices: An introduction. Sociology of Health \& Illness, 36(2), 157-162.

De Maio, F. G., \& Kemp, E. (2010). The deterioration of health status among immigrants to Canada. Global Public Health, 5(5), 462-478.

Dehghani, F., Omidi, F., Yousefinejad, S., \& Taheri, E. (2020). The hierarchy of preventive measures to protect workers against the COVID-19 pandemic: A review. Work, 67(4): 771-777. https:// doi.org/10.3233/WOR-203330.

European Centre for Disease Prevention and Control. (2020). COVID-19 clusters and outbreaks in occupational settings in the EU/EEA and the UK, 11 August 2020. Stockholm, Sweden: ECDC. https://www. ecdc.europa.eu/sites/default/files/documents/COVID-19-inoccupational-settings.pdf.

Frank, L., Fisher, L., \& Saulnier, C. (2020). 2020 report card on child and family poverty in Nova Scotia: Willful neglect? Halifax: Canadian Centre for Policy Alternatives. https://www. policyalternatives.ca/sites/default/files/uploads/publications/Nova\% 
20 Scotia $\% 20$ Office $/ 2020 / 12 /$ Child $\% 20$ poverty $\% 20$ report $\%$ 20card\%202020.pdf.

Garnier, R., Benetka, J. R., Kraemer, J., \& Bansal, S. (2021). Socioeconomic disparities in social distancing during the COVID19 pandemic in the United States: Observational study. Journal of Medical Internet Research, 23(1), e24591.

Günther, T., Czech-Sioli, M., Indenbirken, D., Robitaille, A., Tenhaken, P., Exner, M., et al. (2020). SARS-CoV-2 outbreak investigation in a German meat processing plant. EMBO Molecular Medicine, 12(12), e13296.

Haan, M. (2011). The residential crowding of immigrants in Canada, 19712001. Journal of Ethnic and Migration Studies, 37(3), 443-465.

Haworth-Brockman, M., \& Betker, C. (2020). Measuring what counts in the midst of the COVID-19 pandemic: equity indicators for public health. National Collaborating Centre for Infectious Disease \& National Collaborating Centre for Determinants of Health. https://nccid.ca/publications/measuring-what-counts-in-the-midstof-the-covid-19-pandemic-equity-indicators-for-public-health/.

Hecker, S. (2020). Hazard pay for COVID-19? Yes, but it's not a substitute for a living wage and enforceable worker protections. $N E W$ SOLUTIONS: A Journal of Environmental and Occupational Health Policy, 30(2), 95-101.

Heisz, A., \& Schellenberg, G. (2004). Public transit use among immigrants. Canadian Journal of Urban Research, 13(1), 170-191.

Jay, J., Bor, J., Nsoesie, E. O., Lipson, S. K., Jones, D. K., Galea, S., \& Raifman, J. (2020). Neighbourhood income and physical distancing during the COVID-19 pandemic in the United States. Nature Human Behaviour, 4(12), 1294-1302.

Krumpal, I. (2013). Determinants of social desirability bias in sensitive surveys: A literature review. Quality \& Quantity, 47(4), 2025-2047.

Lachapelle, U., \& Pinto, D. G. (2016). Longer or more frequent walks: Examining the relationship between transit use and active transportation in Canada. Journal of Transport \& Health, 3(2), 173-180. https://doi.org/10.1016/j.jth.2016.02.005.

Lau, J. T. F., Yang, X., Tsui, H., \& Kim, J. H. (2003). Monitoring community responses to the SARS epidemic in Hong Kong: From day 10 to day 62. Journal of Epidemiology and Community Health, 57(11), 864. https://doi.org/10.1136/jech.57.11.864.

Link, B. G., \& Phelan, J. (1995). Social conditions as fundamental causes of disease. Journal of Health and Social Behavior, 80-94.

McClure, E. S., Vasudevan, P., Bailey, Z., Patel, S., \& Robinson, W. R. (2020). Racial capitalism within public health-how occupational settings drive COVID-19 disparities. American Journal of Epidemiology. https://doi.org/10.1093/aje/kwaa126.

Naimi, A. I., Schnitzer, M. E., Moodie, E. E. M., \& Bodnar, L. M. (2016). Mediation analysis for health disparities research. American Journal of Epidemiology, 184(4), 315-324. https://doi.org/10.1093/aje/ kwv329.

Newson, R. B. (2013). Attributable and unattributable risks and fractions and other scenario comparisons. The Stata Journal, 13(4), 672-698.

Novac, S., Darden, J., Hulchanski, D., \& Seguin, A.-M. (2002). Housing discrimination in Canada: The state of knowledge. Ottawa: Canada Mortgage and Housing Corporation. http://www.hnc.utoronto.ca/ pdfs/home/Novac_Discrimination-Lit-Re.pdf.

Public Health Agency of Canada. (2020). Physical distancing: How to slow the spread of COVID-19. Retrieved from https:/www.canada. ca/en/public-health/services/publications/diseases-conditions/ social-distancing.html.

Public Health Agency of Canada. (2021). Coronavirus disease 2019 (COVID-19): Epidemiology update. Retrieved from https://healthinfobase.canada.ca/covid-19/epidemiological-summary-covid-19cases.html.

Quah, S. R., \& Hin-Peng, L. (2004). Crisis prevention and management during SARS outbreak, Singapore. Emerging Infectious Diseases, 10(2), 364-368. https://doi.org/10.3201/eid1002.030418.
Rosenstock, I. M. (1974). The health belief model and personal health behavior. Health Education Monographs, 2(4), 354-386. https:// www.jstor.org/stable/45240623.

Semenza, J. C. (2010). Strategies to intervene on social determinants of infectious diseases. Eurosurveillance, 15(27), 19611.

Sen, A. (1993). Capability and well-being. In The Quality of Life (Vol. 30).

Solar, O., \& Irwin, A. (2010). A conceptual framework for action on the social determinants of health. Social Determinants of Health Discussion Paper 2 (Policy and Practice). Geneva: World Health Organization. Available at: https://www.who.int/social determinants/corner/SDHDP2.pdf?ua=1.

Solis, J., Franco-Paredes, C., Henao-Martínez, A. F., Krsak, M., \& Zimmer, S. M. (2020). Structural vulnerability in the U.S. revealed in three waves of COVID-19. The American Journal of Tropical Medicine and Hygiene, 103(1), 25-27. https://doi.org/10.4269/ ajtmh.20-0391.

Statistics Canada. (2020a). Canadian Perspectives Survey Series 1: Impacts of COVID-19 (CPSS-COVID). Ottawa: Statistics Canada. https://www23.statcan.gc.ca/imdb/p2SV.p1?Function= getSurvey\&Id=1280240.

Statistics Canada. (2020b). Table 14-10-0287-01 Labour force characteristics, monthly, seasonally adjusted and trend-cycle, last 5 months [March 2019, Canada, both sexes]. Ottawa: Statistics Canada. hhttps://doi.org/10.25318/1410028701-eng.

Statistics Canada. (2020c). Table 14-10-0287-02 Labour force characteristics by age group and sex, seasonally adjusted. The Daily. Ottawa: Statistics Canada. https://www150.statcan.gc.ca/n1/dailyquotidien/200207/t001a-eng.htm.

Statistics Canada. (2020d). User guide: Canadian Perspectives Survey Series 1 Impacts of COVID-19. Ottawa: Statistics Canada. https:// www.statcan.gc.ca/eng/survey/household/5311.

Sy, K. T. L., Martinez, M. E., Rader, B., \& White, L. F. (2020). Socioeconomic disparities in subway use and COVID-19 outcomes in New York City. American Journal of Epidemiology, kwaa277. https://doi.org/10.1093/aje/kwaa277.

Tam, T. (2021). From risk to resilience: An equity approach to COVID-19. Chief Public Health Officer of Canada Report. Ottawa: Government of Canada. https://www.canada.ca/en/public-health/corporate/publications/ chief-public-health-officer-reports-state-public-health-canada/from-riskresilienceequity-approach-covid-19.html.

Tan, X., Li, S., Wang, C., Chen, X., \& Wu, X. (2004). Severe acute respiratory syndrome epidemic and change of people ' $\mathrm{s}$ health behavior in China. Health Education Research, 19(5), 576-580. https://doi.org/10.1093/her/cyg074.

Upshaw, T. L., Brown, C., Smith, R., Perri, M., Ziegler, C., \& Pinto, A. D. (2021). Social determinants of COVID-19 incidence and outcomes: A rapid review. PLoS One, 16(3), e0248336.

VanderWeele, T. (2015). Explanation in causal inference. In Methods for mediation and interaction. Oxford University Press.

VanderWeele, T. J. (2016). Mediation analysis: A practitioner's guide. Annual Review of Public Health, 37(1), 17-32. https://doi.org/10. 1146/annurev-publhealth-032315-021402.

Vogel, L. (2020). COVID-19: A timeline of Canada's first-wave response. CMAJ News.

von Lengerke, T., Gohl, D., \& Babitsch, B. (2014). Re-revisiting the behavioral model of health care utilization by Andersen: A review on theoretical advances and perspectives. In C. Janssen, E. Swart, \& T. von Lengerke (Eds.), Health Care Utilization in Germany: Theory, Methodology, and Results (pp. 11-28). Springer New York.

Weill, J. A., Stigler, M., Deschenes, O., \& Springborn, M. R. (2020). Social distancing responses to COVID-19 emergency declarations strongly differentiated by income. Proceedings of the National Academy of Sciences, 117(33), 19658-19660.

Williams, R. (2012). Using the margins command to estimate and interpret adjusted predictions and marginal effects. The Stata Journal, 12(2), 308-331. 
Yang, J., Park, E. C., Lee, S. A., \& Lee, S. G. (2019). Associations between hand hygiene education and self-reported hand-washing behaviors among Korean Adults during MERS-CoV outbreak. Health Education \& Behavior, 46(1), 157-164. https://doi.org/10. $1177 / 1090198118783829$.
Yearby, R., \& Mohapatra, S. (2020). Structural discrimination in COVID-19 workplace protections. Health Affairs Blog, 2020.

Publisher's note Springer Nature remains neutral with regard to jurisdictional claims in published maps and institutional affiliations. 